\title{
Afforestation Effects on Soil Carbon Storage in the United States: A Synthesis
}

\section{E. Nave*}

University of Michigan

Biological Station and Department of

Ecology and Evolutionary Biology

Pellston, MI 49769

\section{W. Swanston}

USDA-Forest Service

Northern Research Station

Houghton, MI 49931

\section{U. Mishra}

Lawrence-Berkeley National Laboratory Berkeley, CA 94720

currently at

Argonne National Laboratory Environmental Science Division Argonne, IL 60439

\section{K. J. Nadelhoffer}

University of Michigan Biological Station and Department of Ecology and Evolutionary Biology Pellston, MI 49769

\begin{abstract}
Afforestation (tree establishment on nonforested land) is a management option for increasing terrestrial $\mathrm{C}$ sequestration and mitigating rising atmospheric carbon dioxide because, compared to nonforested land uses, afforestation increases $C$ storage in aboveground pools. However, because terrestrial ecosystems typically store most of their $\mathrm{C}$ in soils, afforestation impacts on soil organic carbon (SOC) storage are critical components of ecosystem $\mathrm{C}$ budgets. We applied synthesis methods to identify the magnitude and drivers of afforestation impacts on SOC, and the temporal and vertical distributions of SOC change during afforestation in the United States. Meta-analysis of 39 papers from 1957 to 2010 indicated that previous land use drives afforestation impacts on SOC in mineral soils (overall average $=$ $+21 \%)$, but mined and other industrial lands $(+173 \%)$ and wildlands $(+31 \%)$ were the only groups that specifically showed categorically significant increases. Temporal patterns of SOC increase were statistically significant on former industrial and agricultural lands (assessed by continuous metaanalysis), and suggested that meaningful SOC increases require $\geq 15$ and 30 $\mathrm{yr}$ of afforestation, respectively. Meta-analysis of ${ }^{13} \mathrm{C}$ data demonstrated the greatest SOC changes occur at the surface soil of the profile, although partial replacement of $C$ stocks derived from previous land uses was frequently detectable below $1 \mathrm{~m}$. A geospatial analysis of 409 profiles from the National Soil Carbon Network database supported ${ }^{13} \mathrm{C}$ meta-analysis results, indicating that transition from cultivation to forest increased A horizon SOC by $32 \%$. In sum, our findings demonstrate that afforestation has significant, positive effects on SOC sequestration in the United States, although these effects require decades to manifest and primarily occur in the uppermost (and perhaps most vulnerable) portion of the mineral soil profile.
\end{abstract}

Abbreviations: $\mathrm{BD}$, bulk density; $\mathrm{Cl}$, confidence interval; $\mathrm{MAP}$, mean annual precipitation; MAT, mean annual temperature; SOC, soil organic carbon.

S cientifically informed prediction, projection, and management of soil and related ecosystem resources in the United States require accurate accounting of SOC stocks under diverse land use and management practices. This is not only because terrestrial ecosystems store the bulk of their C in soils (Jobbágy and Jackson, 2000), but also because SOC is a fundamental driver of critical ecosystem processes and services including nutrient cycling, water retention, and biological carbon sequestration (Lal, 2004; Post et al., 2004). Furthermore, while the general and broad-scale effects of basic management activities (e.g., fertilization or biomass removal) on $\mathrm{C}$ production and storage in aboveground ecosystem pools are fairly well understood (Birdsey et al., 2006; Fox, 2000; Ludwig et al., 2011; Vance, 2000), management impacts on belowground C stocks (including SOC) at

\footnotetext{
Soil Sci. Soc. Am. J. 77:1035-1047

doi:10.2136/sssaj2012.0236

Received 1 Aug. 2012

*Corresponding author (lukenave@umich.edu).

(C) Soil Science Society of America, 5585 Guilford Rd., Madison WI 53711 USA

All rights reserved. No part of this periodical may be reproduced or transmitted in any form or by

any means, electronic or mechanical, including photocopying, recording, or any information storage and retrieval system, without permission in writing from the publisher. Permission for printing and for reprinting the material contained herein has been obtained by the publisher.
} 
similarly broad conceptual and spatial scales are much less understood. Recent reviews have demonstrated measureable impacts of fertilization (Alvarez, 2005; Ladha et al., 2011; Nave et al., 2009) or biomass removal (Nave et al., 2010; Thiffault et al., 2011; Wilhelm et al., 2004) on SOC in a variety of ecosystems, and others have addressed questions of SOC change when management involves land use transitions including afforestation (Guo and Gifford, 2002, Post and Kwon, 2000; Berthrong et al., 2009; Laganiere et al., 2010). During afforestation, increases in aboveground C stocks can be expected, owing to the establishment and growth of trees on lands that previously lacked significant woody biomass, and trajectories of $\mathrm{C}$ accumulation in forest biomass are precisely quantified for afforesting lands in the United States. (Smith et al., 2006). However, scientific understanding of SOC changes for $\mathrm{C}$ accounting purposes lags behind knowledge of aboveground $\mathrm{C}$ accumulation, and in the midst of this need for information that is specific to the United States the global scope of afforestation-SOC synthesis papers makes their direct application to the $\mathrm{C}$ balance of U.S. lands uncertain. Furthermore, existing global afforestation-SOC reviews are mostly restricted to intentionally established forests, while in the United States a large amount of forest regrowth has occurred on lands managed for natural regeneration of forest cover (Birdsey et al., 2006).

Global-scale quantitative reviews of SOC change during afforestation have demonstrated some consistent patterns. First, all such work reveals that previous land use significantly impacts the amount or rate of SOC change during afforestation. Second, coniferous species tend to decrease SOC in mineral soils, while broadleaf trees show no effect or an increase (Laganiere et al., 2010; Berthrong et al., 2009; Guo and Gifford, 2002). These large-scale reviews have also revealed relationships between SOC change and soil or environmental factors that are logically consistent with understanding of the factors controlling SOC accumulation. For example, the amount of SOC accumulation during forest regrowth tends to approximate the quantity lost to cultivation on agricultural afforestations (Guo and Gifford, 2002), and the amount of change in SOC during afforestation is typically a function of time elapsed since the prior land use (Guo and Gifford, 2002; Post and Kwon, 2000). Such relationships are logical if it is expected that in SOC stocks in a given location equilibrate over time in response to factors such as the productivity and architecture of vegetation, climate, and the physical characteristics of the soil. Further examples come from reviews indicating that climatic factors modulate $S O C$ responses to afforestation, and that the capacity for SOC accumulation during afforestation is positively related to soil clay content (Guo and Gifford, 2002; Laganiere et al., 2010). In light of this diversity of drivers, and the rarely reported result in the review literature that most of the variability in SOC change during afforestation is unattributed, a quantitative review of afforestation studies directly relevant to the United States is necessary for accurate C accounting. To close this geographic knowledge gap and produce a set of products for land managers and policymakers concerned with $\mathrm{C}$ accounting, we compiled relevant information from aca- demic and agency sources and then applied synthesis methods (meta-analysis and a community soil C database) to the question of $\mathrm{SOC}$ changes following afforestation. We address four primary questions in our analyses: (i) What factors drive variation in the effects of afforestation on SOC? (ii) What temporal patterns underlie SOC responses to afforestation? (iii) How are afforestation effects on SOC distributed throughout the soil profile? (iv) Do point-based, national-scale data indicate that afforestation has increased SOC in formerly agricultural soils?

\section{METHODS \\ Meta-Analysis: Literature Searching and Inclusion Criteria}

The meta-analysis portion of this synthesis followed the methods of Nave et al. (2010). We searched the peer-reviewed and gray literature via the online databases ISI Web of Science, BIOSIS, Agricola, and CAB Direct with keywords such as forest management, afforestation, agroforest, plantation, and soil carbon. We also checked references of papers on afforestation and soil change. By inspecting $>7500$ references returned by literature searches and reference checking, we found 39 publications that met our inclusion criteria of reporting control (nonafforested) and treatment (afforested) mineral soil $\mathrm{C}$ values, and being conducted in the United States (or adjacent Canadian provinces, to increase data availability). Acceptable control-treatment comparisons were (i) time series measurements (pre- vs. postafforestation), (ii) paired plot designs in which some plots were and others were not afforested, and (iii) chronosequences. In the case of most chronosequences, the control plot was a year-zero plot with no afforestation in progress. However, to maximize data availability for this analysis, we included several publications in which the "control" plot of the chronosequence had been undergoing afforestation for 1 to $10 \mathrm{yr}$. Calculating soil C response ratios relative to a non-zero baseline may underestimate the overall effects of afforestation, but since a primary goal of this meta-analysis was to assess changes in soil $\mathrm{C}$ over time following afforestation, we corrected for non-zero controls by expressing the age of the treatment (afforested) plots relative to the youngest plot. For example, for one paper with chronosequence plot ages of $1,3,7$, and $14 \mathrm{yr}$ since agricultural abandonment (Markewitz et al., 2002), we used the 1 -yr plot as the control condition and coded the others as treatment plots with 2, 6, and 13 yr elapsed since afforestation began. Thus, while the overall effect of afforestation on soil $\mathrm{C}$ change may be underestimated for this example, we assume that the temporal pattern of that change over 13 to 14 $\mathrm{yr}$ is robust whether the initial control plot had been under afforestation for 0 or $1 \mathrm{yr}$. Note that for tests not explicitly applied to temporal questions, afforestation effect sizes were derived from studies spanning a wide temporal scale, from short-term (several years) to long-term (decades or even $>100 \mathrm{yr}$ ).

To the degree possible, we used published estimates of soil $\mathrm{C}$ pool size (C storage; SOC) as the response variable for this analysis. When papers reported only soil $\mathrm{C}$ concentrations and bulk densities, we calculated the SOC stock from these terms. 
For a small number of papers that reported soil \%C but no bulk density, we used the gap-filling approach of Post and Kwon (2000) to estimate soil bulk density and subsequently calculated the SOC stock. Finally, for the small number of papers that reported soil organic matter rather than SOC, we assumed that $50 \%$ of the soil organic matter was $\mathrm{C}$ and adjusted the reported values accordingly.

In an effort to identify sources of variation in the effects of afforestation on SOC, we extracted metadata (predictor variables) from each publication, including temporal and climatic data, soil properties, and treatment and analytical methods. One important distinction in the soil properties category was the soil layer sampled. As we did not include data from O horizons in this analysis, we extracted data for every mineral soil layer reported in each publication, and coded the data so that we could test for differences between layers we coded in the database as surface, middle, and deep mineral soil. Soil layers were coded according to the midpoints of their sampling depths; surface mineral soils had midpoints $\leq 10 \mathrm{~cm}$, middle soil layers had sampling midpoints of 11- to 20-cm depth, and deep soil layers had midpoints $>20 \mathrm{~cm}$. Regarding our classification of previous land use, we categorized studies if metadata were descriptive enough to ascertain which land use occurred before afforestation. Land use categories were (i) cultivated agricultural lands, (ii) agricultural lands actively used for livestock forage production (whether grazed pasture or was unknown, (iv) industrial substrates (slag, mine spoils, overburden, and barrens), and (v) wildlands (wild grasslands without intensive grazing or haying). The complete list of factors by which we categorized the response ratios in the database appears in Table 1.

\section{Meta-Analysis: Statistical Approach}

Meta-analysis quantifies change in a parameter (i.e., the "efmowed hayland), (iii) agricultural lands whose specific history

yield $k=2$ response ratios, or "studies." Because it has no units, the effect size $R$ can be used to compare experiments reporting data in different units (Hedges et al., 1999). After back transformation $\left[\mathrm{e}^{\ln (R)}\right], R$ can be conceptualized as the proportional or percentage change in SOC relative to its control value. When error terms and sample sizes are reported for each $\bar{X}^{\mathrm{T}}$ and $\bar{X}$ C, a parametric, weighted meta-analysis is possible, but many publications did not report these data. Therefore, to include as many as possible, we used unweighted meta-analysis, in which all studies in the data set are assigned an equal variance. In an unweighted meta-analysis, distributional statistics (mean effect sizes and confidence intervals) are generated by bootstrapping, which estimates distributional statistics by iteratively permuting and resampling the data set. Since it makes no parametric assumptions and generates distributional statistics from the available data, bootstrapping typically produces wider, more conservative confidence intervals (Adams et al., 1997). We performed meta-analyses using MetaWin (Sinauer Associates, Sunderland, MA USA), with 999 iterations.

Meta-analysis is useful for identifying factors that drive variation in SOC responses to afforestation. Similar to ANOVA, meta-analysis partitions the total variance $\left(Q_{t}\right.$, the total heterogeneity) of a distribution of observations into its within- and between-group components ( $Q_{\mathrm{w}}$ and $Q_{\mathrm{b}}$, respectively) according to groups defined by any categorical factor (Hedges and Olkin, 1985). A categorical factor that defines groups of response ratios with large $Q_{\mathrm{b}}$ is a better predictor of variation than a categorical factor with low $Q_{\mathrm{b}}$, and accordingly has a lower $P$ value. If sample sizes and data structure permit, $Q_{\mathrm{b}}$ assessments can be conducted hierarchically by identifying the best predictor of variation in the entire dataset, splitting the dataset into the groups defined by that predictor, and then repeating the process within each group to elucidate underlying sources of variation (Nave et al., 2010). In the present study, we used $Q_{\mathrm{b}}$ and $P$ statistics to idenfect size") in response to an experimental treatment, which may be applied across a wide range of experimental systems and conditions. We used the $\ln$-transformed response ratio $R$ to estimate treatment effect size:

$$
\ln (R)=\ln \left(\bar{X}^{\mathrm{T}} / \bar{X}^{\mathrm{C}}\right)
$$

where $\bar{X}^{\mathrm{T}}$ is the mean SOC value of treatment (afforested) observations and $\bar{X}^{\mathrm{C}}$ is the mean SOC value of control observations for a given set of experimental conditions. The number of response ratios $(k)$ in a paper depends on how many sets of experimental conditions are imposed. For example, one publication with SOC data from a control plot and from plantations of two different ages would

Table 1. Predictor variables tested using meta-analysis.

\section{Factor}

\section{Woody establishment type natural; planted}

Previous land use

Forest type

Soil layer

Soil texturet

Analytical method

Soil taxonomic order

Region‡

Time category

Time

Mean annual temperature

Mean annual precipitation

Control soil C pool size§

cont samp
Levels

agriculture- cultivated, ag- forage, ag- unknown, industrial, wildland
conifer; hardwood; mixed
surface; middle; deep
coarse; fine
dry combustion; loss on ignition; wet oxidation
Alfisol; Andisol; Aridisol; Entisol; Inceptisol; Mollisol; Spodosol; Ultisol
Hawai'i; Northeast; Northern Lakes; Northern Prairie; Pacific Northwest;
Rocky Mountain North; Rocky Mountain South; South Central, Southeast
$<5,5-14,15-24,25-34,35-44,45-54,55-64,65-74,75-84,85-94$,
$95-104,105-114,115-124,125-135$ yr
continuous (range: $1-131$ yr)
continuous (range: $2.7-22.4^{\circ}$ )
continuous (range: $219-4600$ mm)
continuous (range: $0.3-229 \mathrm{Mg} \mathrm{C} \mathrm{ha-1)}$
continuous (range: $1-200 \mathrm{~cm}$ )


tify the best predictor of variation in the overall meta-analysis (previous land use), then conducted further meta-analyses on each significantly different land use category. Because the three previous agricultural land uses (cultivated, forage, unknown agricultural use) had the same overall response to afforestation (no net change in SOC), they were grouped and analyzed together as a single, well-replicated previous land use category, permitting full $\mathrm{Q}_{\mathrm{b}}$ analysis without confounded data structure. However, to avoid outlier bias, it was necessary to remove 12 response ratios from this category ( $>2 \sigma$ criterion; $<6 \%$ of observations) before continuing into hierarchical $Q_{\mathrm{b}}$ analysis. Hierarchical $Q_{\mathrm{b}}$ analysis was not performed for industrial or wildland previous land uses due to confounded data structure.

In addition to identifying categorical variables that influenced soil $\mathrm{C}$ responses to afforestation, we tested several continuously varying factors (Table 1) as predictors of variation using continuous meta-analyses. Continuous meta-analysis is similar to the variance-partitioning process of $Q_{\mathrm{b}}$ analysis, in that the heterogeneity among $\mathrm{k}$ observations is partitioned into that which is explained by a linear model $\left(Q_{\mathrm{m}}\right)$ and that which constitutes the residual error variance $\left(Q_{\mathrm{e}}\right)$. In this way, continuous meta-analysis is the same as the ANOVA F-test for significance of linear regression models (Hedges and Olkin, 1985). Because MetaWin calculates its slope and intercept terms for continuous meta-analysis using the same matrices as simple linear regression (Rosenberg et al., 2000) but does not have the capability to add confidence or prediction bands, we used linear regression in SigmaPlot (SYSTAT Software, San Jose, CA) to obtain confidence intervals for point estimates that were calculated from continuous meta-analytic models. In all tests, including overall, $Q_{\mathrm{b}}$, and continuous meta-analyses, we accepted results with $P$ $<.05$ as statistically significant, and effect sizes were considered significant for groups with $95 \%$ confidence intervals that did not overlap $0 \%$ change in SOC.

Our data synthesis generated $282 \mathrm{SOC}$ response ratios from 39 papers published between 1957 and 2010. The full dataset is available on the National Soil Carbon Network website (http:// www.soilcarb.net). Publications that were used as data sources for this meta-analysis are identified in Appendix A.

\section{Meta-Analysis of Soil $\delta^{13} \mathrm{C}$}

To resolve the depth distribution of SOC change following afforestation, we conducted a supplementary meta-analysis using data from afforestations on lands previously dominated by $\mathrm{C} 4$ vegetation. Because the $\mathrm{C} 4$ photosynthetic pathway produces fixed-C ranging from -13 to $-11 \% 0 \delta^{13} \mathrm{C}$, soils under $\mathrm{C} 4$ vegetation tend to have similarly enriched $\delta^{13} \mathrm{C}$, which becomes more depleted when trees are established and begin adding $\mathrm{C} 3$ detritus with $\delta^{13} \mathrm{C}$ of -30 to $-24 \%$ to the soil (Boutton et al., 1998). The exact proportions of $\mathrm{C} 3$ vs. C4-derived SOC in a soil are calculated using site-specific $\delta^{13} \mathrm{C}$ values for $\mathrm{C} 3$ vs. $\mathrm{C} 4$ soils or detritus inputs (i.e., end-members) and a mass balance equation which generally takes the form:

$$
p \mathrm{SOC}_{3}=\left(\mathrm{d}-\delta_{0}\right) /\left(\delta_{\mathrm{c}}-\delta_{0}\right)
$$

where, for any soil sample, $\mathrm{SSOC}_{3}$ is the proportion of SOC derived from $C 3$ vegetation, $d$ is the $d^{13} \mathrm{C}$ of the soil sample, $d_{0}$ is the $\mathrm{d}^{13} \mathrm{C}$ of a soil under $\mathrm{C} 4$ vegetation, and $\mathrm{d}_{\mathrm{c}}$ is the $\mathrm{d}^{13} \mathrm{C}$ of the $\mathrm{C} 3$ (forest) detritus inputs. The publications we gathered for this portion of the meta-analysis used structurally different but conceptually identical versions of this equation, all of which are based on the same assumptions and share a common method of estimating, by difference, the proportion of SOC derived from either type of vegetation. For greater detail on these mixingmodel equations, including assumptions and input values, refer to Balesdent et al. (1988), Boutton et al. (1998), Vitorello et al. (1989), or any of the references in Appendix B. To conduct this portion of the meta-analysis, using the publications in Appendix $\mathrm{B}$, we chose $\mathrm{pSOC}_{3}$ as the response parameter of interest and extracted this value from the control soil and from the afforested soil in each paper. Therefore, the response ratio in this part of the analysis $\left(R_{\mathrm{SOC} 3}\right)$ corresponds to the net change in $\mathrm{pSOC}_{3}$ due to afforestation. In all other methodological regards, including metadata and study categorization, this portion of the metaanalysis follows the procedures outlined in the above sections Meta-analysis: Literature Searching and Inclusion Criteria and Meta-analysis: Statistical Approach.

\section{Geospatial Analysis: Assumptions and Initial Data Filtering}

To interpret and assess the accuracy of our meta-analysis results, we conducted hypothesis testing using the spatially explicit soil C database of the National Soil Carbon Network (NSCN), which integrates soils information with land cover data from the National Land Cover Database 2001 (Multi-Resolution Land Characteristics Consortium, 2011). We hypothesized that afforestation of cultivated agricultural lands would significantly increase $\mathrm{C}$ storage in the surface mineral horizons of the soil profile, and we tested this hypothesis by comparing Ap horizons from recently forested vs. cultivated soils. Ap horizons are plowed mineral surface soil layers that reflect past homogenization and mixing of surface organic and upper mineral soil layers. Because they tend to originate from mechanical cultivation, Ap horizons usually have a fairly uniform depth, and may remain conspicuous for decades or even centuries after cultivation has ended (Compton and Boone, 2000). Therefore, when an Ap horizon is found in a forest setting, we assumed for this analysis that the forest was established on land that was formerly cultivated. Comparing SOC in these forested vs. cultivated Ap horizons is thus a validation of our meta-analysis results that constrain afforestation effects on former agricultural soils. To ensure comparability across Ap horizons, we selected from the NSCN database only Ap horizons from the United States that were at the surface layer in their profile (i.e., layer top $=0 \mathrm{~cm}$ ) and did not extend any deeper than $50 \mathrm{~cm}$ (layer bottom $\leq 50 \mathrm{~cm}$ ). This pair of criteria assured that the selected Ap horizons originated from soil profiles without $\mathrm{O}$ horizons (which were not considered in 
Table 2. Linear models derived from the NSCN database for gap-filling Ap horizons that were missing either $\% O C$ or $\mathrm{BD}_{\text {samp }}$. Input variables were chosen using best subsets regression with adjusted $r^{2}$ and C-p statistics as criteria.

\begin{tabular}{|c|c|c|c|c|c|}
\hline $\begin{array}{c}\text { Predicted } \\
\text { variable }(Y)\end{array}$ & Input variables $(X)$ & Equation & $n$ & $r^{2}$ & $\boldsymbol{P}$ \\
\hline$\% \mathrm{OC}$ & $\begin{array}{l}X_{1}=\% \mathrm{CaCO}_{3} \\
X_{2}=\% \mathrm{C}_{\text {tot }}\end{array}$ & $Y=-0.00911-\left(0.111 X_{1}\right)+\left(1.020 X_{2}\right)$ & 184 & 0.88 & $<0.001$ \\
\hline$\% \mathrm{OC}$ & $X_{1}=\% \mathrm{C}_{\mathrm{tot}}$ & $Y=0.132+\left(0.930 X_{1}\right)$ & 493 & 0.94 & $<0.001$ \\
\hline $\mathrm{BD}_{\text {samp }}$ & $\begin{array}{l}X_{1}=\mathrm{BD}_{\text {other }} \\
X_{2}=\% \text { silt } \\
X_{3}=\% \text { clay } \\
X_{4}=\% \text { c.frag }\end{array}$ & $Y=0.137+\left(.914 X_{1}\right)-\left(.000791 X_{2}\right)+\left(0.0069 X_{3}\right)-\left(0.000706 X_{4}\right)$ & 3742 & 0.87 & $<0.001$ \\
\hline $\mathrm{BD}_{\text {samp }}$ & $\begin{array}{l}X_{1}=\mathrm{BD}_{\text {whole }} \\
X_{2}=\% \text { silt } \\
X_{3}=\% \text { clay } \\
X_{4}=\% \text { c.frag }\end{array}$ & $Y=0.167+\left(.898 X_{1}\right)-\left(.000871 X_{2}\right)+\left(0.00662 X_{3}\right)-\left(0.00824 X_{4}\right)$ & 3900 & 0.81 & $<0.001$ \\
\hline
\end{tabular}

this paper) and did not come from buried horizons or other deep soil layers. Furthermore, we did not include soils from Alaska in this analysis.

\section{Geospatial Analysis: Gap-Filling and Criteria for Landcover Analysis}

The two key variables necessary to compute SOC stocks in the geospatial analysis (soil $\mathrm{C}$ concentration and bulk density) were not always available for each Ap horizon, leading to gapfilling exercises to estimate them. The final equations for the gap-filling exercises described below are presented in Table 2. Using the 12,375 Ap horizons from the NSCN Database that met the criteria in section 2.4 , we derived regression functions to gap-fill \% organic C (\%OC) and root-free fine earth bulk density $\left(\mathrm{BD}_{\text {samp }}\right)$ values for each Ap that was missing one of these measurements. Ap horizons missing both of these variables were excluded from the analysis. We chose \%OC instead of total $\mathrm{C}$ concentration $\left(\% \mathrm{C}_{\text {tot }}\right)$ because the former was more commonly reported, and more accurate for assessing afforestation effects on SOC. For all Ap horizons with measures of $\% \mathrm{C}_{\text {tot }}$ and inorganic $\mathrm{C}$ concentration, we used linear regression to model $\% \mathrm{OC}$ as a function of these two predictors. The organic $\mathrm{C}$ concentrations of Ap horizons lacking inorganic $\mathrm{C}$ concentration data were predicted as a simple linear function of $\% \mathrm{C}_{\text {tot }}$. For bulk densities, we chose $\mathrm{BD}_{\text {samp }}$ (root-free, $<2 \mathrm{~mm}$ ) rather than $\mathrm{BD}_{\text {whole }}$ or $\mathrm{BD}_{\text {other }}$ (see NSCN database for full definitions), because the latter two metrics are based on subjective estimation and variable methods, respectively. When $\mathrm{BD}_{\text {samp }}$ was not available, we used best subsets regression to predict $\mathrm{BD}_{\text {samp }}$ from a combination of $\mathrm{BD}_{\text {whole }}$ or $\mathrm{BD}_{\text {other }}$ and the soil's particle-size distribution (\% sand, silt, clay, and coarse fragments).

After applying the gap-filling equations (Table 2) to the Ap horizons with missing data, we filtered all Ap horizons according to two criteria before assessing land cover effects: (i) each Ap horizon had to originate from one of the Northern Prairie States (ND, SD, NE, KS, IA, MO, IL, IN [Smith et al., 2006]), and (ii) each Ap horizon had to have been sampled between 1995 and 2009. The first criterion was established to mitigate potential sources of inter-regional variation, such as climate, historic trends of land use change or demographic shifts, while the second criterion ensured that all Ap horizons used in the land cover analysis were sampled within $10 \mathrm{yr}$ of the National Land Cover Database classifications (Multi-Resolution Land Characteristics Consortium, 2011) contained in the NSCN database.

\section{Geospatial Analysis: Statistical Methods}

The final Northern Prairie States Ap horizon dataset developed in the previous section Geospatial Analysis: Gap-Filling and Criteria for Landcover Analysis included 386 observations from currently cultivated soils and 23 from afforested soils. We used \%OC, $\mathrm{BD}_{\text {samp }}$, and a horizon thickness of $5 \mathrm{~cm}$ to calculate the SOC pool size of each of these Ap horizons to a standardized, surficial depth. This approach assumes that each Ap horizon had homogenous properties throughout its vertical extent, which we considered to be a reasonable assumption given that these horizons tend to originate from mechanical mixing. Soil organic carbon pool sizes (as well as \%OC and $\mathrm{BD}_{\text {samp }}$ ) were analyzed by

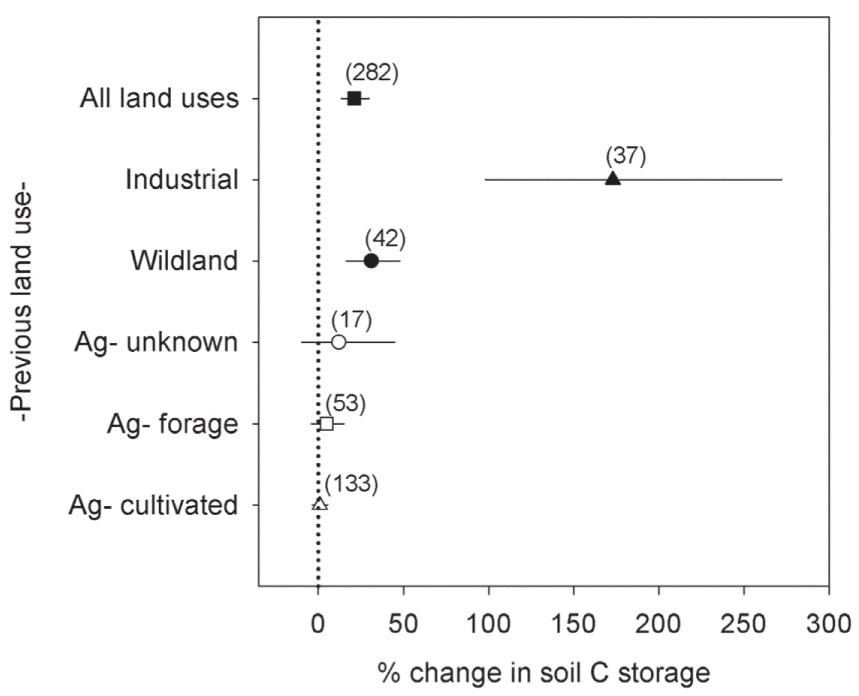

Fig. 1. Effects of afforestation on soil organic carbon (SOC) storage overall and for each previous land use, as calculated using metaanalysis. Points are means with bootstrapped $95 \%$ confidence intervals (Cls) and number of response ratios. Groups with Cls overlapping the dotted reference line show no overall significant change in SOC due to afforestation. 
Table 3. Between-group $(\mathrm{Qb})$ and total heterogeneity $(\mathrm{Qt})$, sample sizes, and $\boldsymbol{P}$ values for the predictor variables tested in the overall meta-analysis of SOC responses to afforestation.

\begin{tabular}{lrrrr}
\multicolumn{1}{c}{ Factors } & Qb & Qt & $\boldsymbol{k}$ & $\boldsymbol{P}$ \\
\hline Categorical factors & & & & \\
Previous land use & 30.3 & 89.9 & 265 & 0.001 \\
Establishment type & 12.4 & 93.8 & 276 & 0.001 \\
Time category & 10.8 & 93.2 & 265 & 0.006 \\
Region & 5.3 & 94.3 & 276 & 0.053 \\
Forest type & 4.5 & 94.3 & 279 & 0.002 \\
Soil texture & 3.9 & 91.3 & 257 & 0.001 \\
Soil layer & 2.0 & 94.4 & 282 & 0.050 \\
Analytical method & 1.9 & 52.7 & 266 & 0.034 \\
Soil taxon. order & 1.1 & 28.5 & 223 & 0.282 \\
Continuous factors & & & & \\
Initial pool size & 6.8 & 94.4 & 282 & 0.001 \\
Time & 6.0 & 93.9 & 265 & 1.000 \\
Sampling midpoint & 1.0 & 94.4 & 282 & 0.028 \\
MAT† & 0.4 & 93.7 & 272 & 0.157 \\
MAP & 0.2 & 93.7 & 272 & 0.233 \\
\hline MAT, mean annul temperature; MAP, mean ann precipitation
\end{tabular}

† MAT, mean annual temperature; MAP, mean annual precipitation.

$t$ test to determine whether and by what amount these properties changed due to afforestation on formerly cultivated soils.

\section{RESULTS}

\section{Meta-Analysis: Overall Results}

Our meta-analysis of the literature showed that afforestation significantly increased SOC, although the overall increase (averaging $21 \%$ across all studies) was driven by large SOC increases associated with specific previous land uses (Fig. 1). Accordingly, previous land use was the most significant source of variation among studies (Table 3 ), with afforestation increasing SOC on industrial substrates $(+173 \%)$ and wildlands $(+31 \%)$.

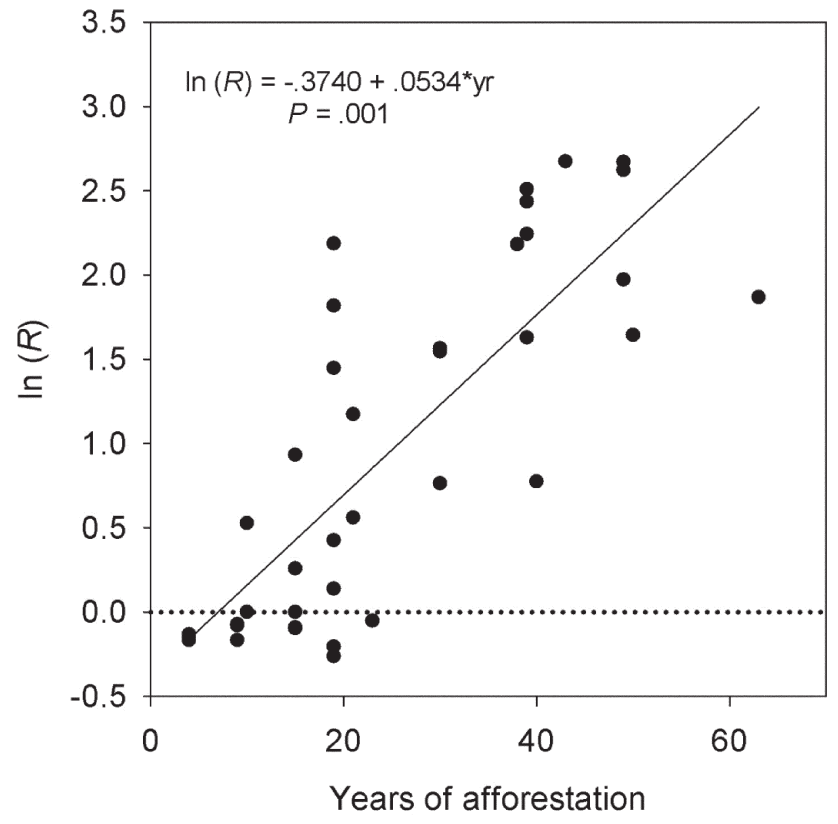

Fig. 2. Net change in $\mathrm{C}$ storage of industrial substrates as a function of time. Points plotted are individual, In-transformed response ratios. The dotted reference line indicates no net change in soil carbon storage due to afforestation. Best-fit line statistics correspond to continuous meta-analysis results.
Table 4. Table showing soil organic carbon (SOC) changes over time during afforestation of industrial substrates. $\dagger$

\begin{tabular}{|c|c|c|}
\hline Time interval & Mean change & $95 \%$ confidence interval \\
\hline $\mathrm{yr}$ & $\%$ & \\
\hline$<5$ & -21.4 & $(-47.1,26.4)$ \\
\hline $5-15$ & 17.4 & $(-14.0,60.4)$ \\
\hline $15-25$ & 100.2 & $(59.3,152.0)$ \\
\hline $25-35$ & 241.4 & $(173.4,327.4)$ \\
\hline $35-45$ & 482.4 & $(333.5,685.5)$ \\
\hline $45-55$ & 893.4 & $(564.0,1393.9)$ \\
\hline $55-65$ & 1594.5 & $(895.2,2802.6)$ \\
\hline
\end{tabular}

Lands previously under the three agricultural use categories (cultivation, forage, unknown) showed no generalized, significant overall change in SOC and were thus bulked into a single group for further tests aimed at partitioning underlying sources of variation. Partitioning sources of variation within these agricultural studies, as well as the studies within industrial and wildland previous land uses provided further insight into the generalized effects of afforestation on each of the previous land use categories.

\section{Meta-Analysis: Variation within Land Uses}

Afforestation on barren industrial lands caused extremely large, statistically significant increases in SOC. However, aside from the highly significant effect of time ( $P=.001$ [Fig. 2]), variation in SOC change during industrial land afforestations was not attributable to any predictors because of a limited sample size $(k=37)$ and confounded data structure. Inspecting the $95 \%$ confidence intervals for the amount of SOC change across the discrete time periods in Table 4, it is apparent that approximately $15 \mathrm{yr}$ of afforestation are required to significantly increase SOC on industrial substrates, with very large, continued SOC increases continuing through subsequent decades (Table 4). For wildland afforestations, which mostly corresponded to woody encroachment in native grasslands, categorical sources of variation were not testable because of confounded data structure. However, continuous meta-analysis indicated that there was a negative relationship between mean annual precipitation (MAP) and SOC change in the deeper portions of the soil profile (Fig. $3 a)$. On the contrary, afforestation-induced SOC changes in surface soils did not vary with MAP but instead increased significantly with the duration of woody encroachment (Fig. 3b). On former agricultural lands, time was the only significant predictor of afforestation effects on SOC (Table 5). The large scatter of data points around the significant positive slope of the time relationship (Fig. 4) indicates major, additional sources of variation that could not be quantified in this meta-analysis. Across all agricultural afforestations, confidence intervals for discrete time periods suggest at least $35 \mathrm{yr}$ are required to significantly increase SOC, with modest decadal increases thereafter culminating in a $\sim 15 \%$ net increase in SOC storage by the end of the first century (Table 6). 
Meta-Analysis of ${ }^{13} \mathrm{C}$ Data

Synthesis of ${ }^{13} \mathrm{C}$ isotopic data revealed a consistent pattern in the depth distribution of SOC changes following afforestation. All of the papers that used ${ }^{13} \mathrm{C}$ to quantify variation in tree-derived SOC with depth showed the same pattern, with four of six studies showing significant, negative linear relationships with sampling depth (Fig. 5a). Continuous meta-analysis using the entire set of $R_{\mathrm{SOC} 3}$ values indicated that sampling depth was also a highly significant predictor of variation across studies $(P<.001$ [Fig. 5b]). Across the range of sampled depths, the continuous meta-analysis linear fit explained $24 \%$ of the variation $\left(Q_{\mathrm{m}} / Q_{\mathrm{t}}\right)$ in $R_{\mathrm{SOC} 3}$. A nonlinear regression model (expo-

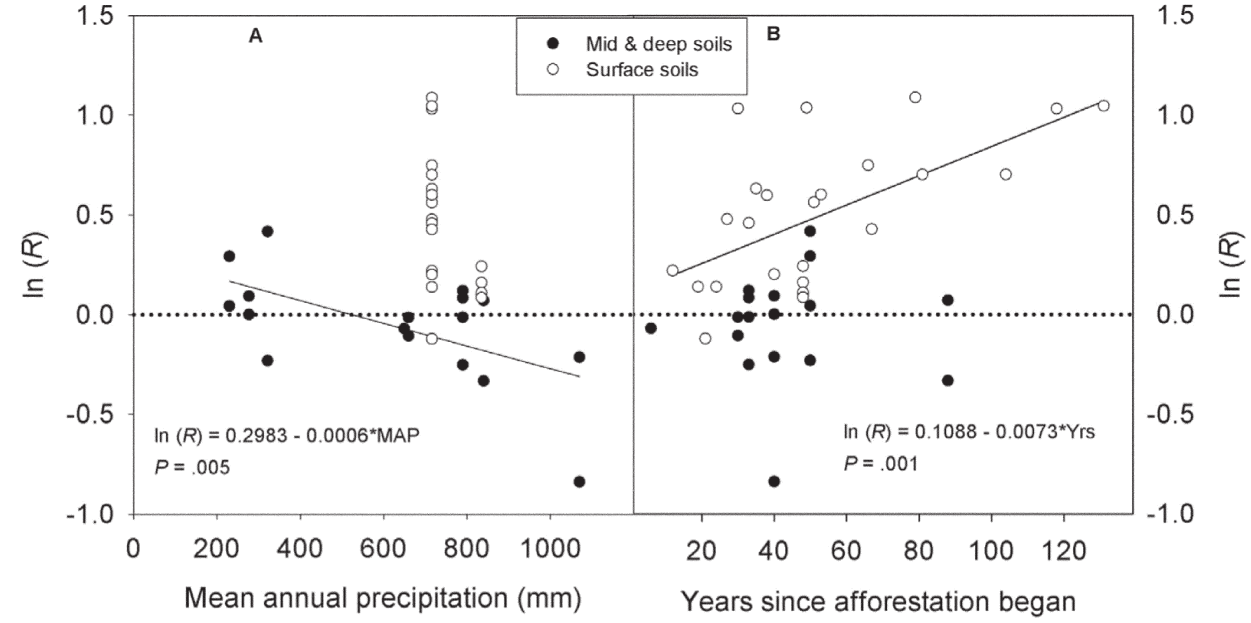

Fig. 3. Net change in wildland soil organic carbon (SOC) as a function of (a) precipitation or (b) time. In both panels, the points plotted are individual, In-transformed response ratios. The dotted reference line indicates no net change in SOC due to afforestation. Best-fit line statistics correspond to continuous meta-analysis results. The best-fit line in Fig. 3a is for mid and deep soils only, while the best-fit line in Fig. 3b corresponds to surface soils only. nential decay) explained more variation in $R_{\mathrm{SOC} 3}$ across depths (33\%), although qualitatively both best-fit models yielded the same result: afforestation causes large net increases in $p \mathrm{SOC}_{3}$ in surface soils, while deeper layers are less responsive.

\section{Geospatial Analysis}

In support of meta-analysis results indicating $\mathrm{SOC}$ increases over time on former agricultural lands (Fig. 4 and Table 6), geospatial analysis using the NSCN database indicated that afforestation has caused measureable changes on surface soil properties and SOC stocks in the Northern Prairie states. Soil C concentration was significantly higher in afforested Ap horizons than Ap horizons from cultivated soils, with the difference in means (2.4 vs. $1.7 \%$ ) corresponding to a relative increase of $38 \%$ (Fig. 6, left). Ap horizon bulk density significantly declined during afforestation, with the two land uses differing by $0.06 \mathrm{~g} \mathrm{~cm}^{-3}$, or $4 \%$ (Fig. 6, right). These shifts in Ap horizon properties translated into an average increase of $4.3 \mathrm{MgC} \mathrm{ha}^{-1}$ in the top $5 \mathrm{~cm}$ of Ap horizons following transition from cultivation to forest cover (a $32 \%$ increase [Fig. 7]).

\section{DISCUSSION}

Our synthesis indicates that afforestation has significantly increased SOC sequestration throughout the United States, with substantial potential for continuing this trend. This record of change and evidence for continued sequestration potential comes from (i) large meta-analytic effect sizes for industrial and wildland afforestations; (ii) temporally resolved SOC increases during afforestation of former industrial and agricultural lands; (iii) consistent ${ }^{13} \mathrm{C}$ patterns indicating a highly responsive surface soil zone where incorporation of forest-derived detritus into the native SOC pool is nearly always large, and often rapid; and (iv) significantly greater SOC in afforested than cultivated Ap horizons distributed across the agricultural midsection of the
United States. However, while these results show that afforestation has a positive impact on SOC sequestration, knowledge gaps identified in this synthesis are evidence that far more work is needed for comprehensive SOC accounting of this type of land use change at all spatial scales.

Afforestation on lands made barren by mineral mining or processing offers substantial opportunities for SOC sequestration. Over the course of the half century of experimental data reported in the literature, forest establishment on these industrial soils increased their SOC stocks by 15 -fold. Where such lands occur, they hold great potential for sequestering SOC and providing attendant soil ecosystem services. However, it is necessary to contextualize this potential in light of our definition for the "control" condition for meta-analysis of industrial afforestations, which we established to maximize data availability and consistency across publications and to ensure the most straightforward interpretation of results: we treated the barren postindustrial

Table 5. Between-group $(\mathrm{Qb})$ and total heterogeneity $(\mathrm{Qt})$, sample sizes, and $\boldsymbol{P}$ values for the predictor variables tested among afforestations on former agricultural land.

\begin{tabular}{lrrrr}
\multicolumn{1}{c}{ Factors } & Qb & Qt & $\boldsymbol{k}$ & $\boldsymbol{P}$ \\
\hline Categorical Factors & & & & \\
Time category & 0.6 & 8.4 & 174 & 0.148 \\
Region & 0.5 & 8.5 & 185 & 0.140 \\
Analytical method & 0.3 & 8.6 & 191 & 0.114 \\
Soil taxon. order & 0.1 & 7.0 & 152 & 0.910 \\
Previous land use & $<0.1$ & 7.7 & 177 & 0.348 \\
Establishment type & $<0.1$ & 8.3 & 185 & 0.402 \\
Soil texture & $<0.1$ & 8.5 & 185 & 0.818 \\
Forest type & $<0.1$ & 8.5 & 188 & 0.555 \\
Soil layer & $<0.1$ & 8.6 & 191 & 0.832 \\
Continuous factors & & & & \\
Time & 0.2 & 8.4 & 175 & 0.016 \\
MAT† & $<0.1$ & 8.3 & 181 & 0.703 \\
MAP & $<0.1$ & 8.3 & 181 & 0.661 \\
Initial pool size & $<0.1$ & 8.6 & 191 & 0.249 \\
Sampling midpoint & $<0.1$ & 8.6 & 191 & 0.467 \\
\hline † MAT, mean annual temperature; MAP, mean annual precipitation.
\end{tabular}




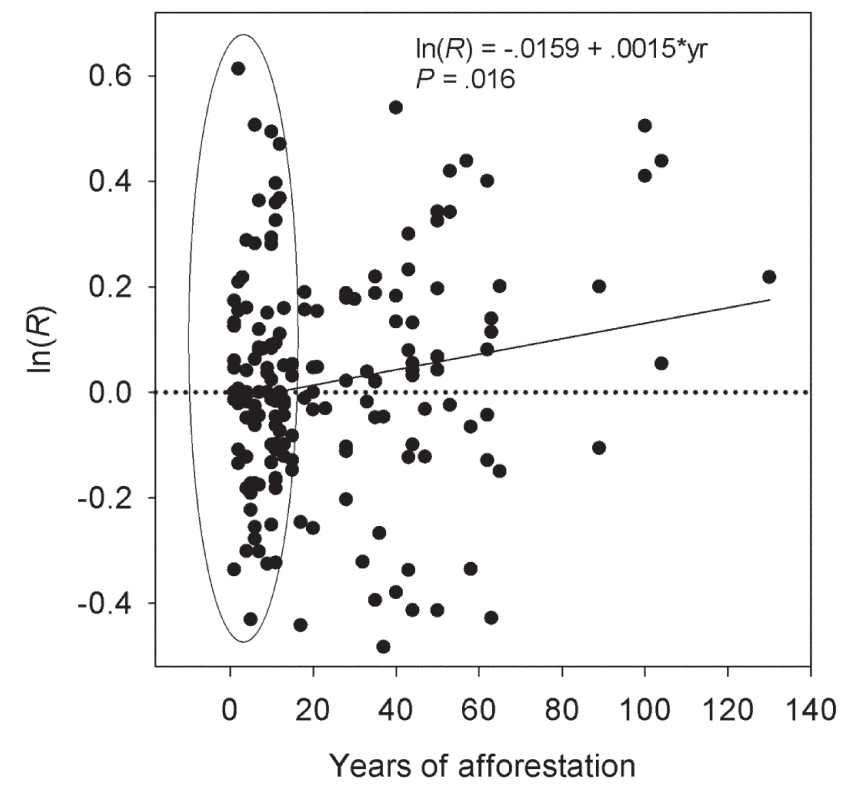

Fig. 4. Net change in carbon storage of former agricultural soils as a function of time. Points plotted are individual, In-transformed response ratios. Note the large amount of variability among response ratios $<15 \mathrm{yr}$ old, denoted by the ellipse surrounding these points on the figure.

substrates created by the removal of native vegetation and soil as the control or starting points for industrial afforestations. Because deconstructing a native ecosystem in this manner releases $\mathrm{C}$ stored in soils and biomass (Amichev et al., 2008), SOC increases during afforestation on such lands do not represent net SOC gains but rather recoveries of lost $\mathrm{C}$.

Our overall meta-analysis results suggest that woody vegetation encroachment into native grasslands of the United States (which we termed "wildland afforestation") generally causes large SOC increases in these ecosystems. However, divergent controls on the SOC responses of wildland soils at different depths and a lack of data for exploring the broader applicability of these controls preclude strong inferences for this previous land use category. Our findings suggest that precipitation affects SOC change in deep soils during woody plant invasion, with drier sites (MAP $<500 \mathrm{~mm} \mathrm{yr}^{-1}$ ) increasing, and wetter sites decreasing SOC storage. This finding supports and is partly based on data synthesized by Jackson et al. (2002), who observed the same relationship and proposed that the dependency of SOC shifts on precipitation during land use change were related to changes in the rooting depth of dominant vegetation. This portion of our meta-analysis highlights that the SOC response of deep soils is in contrast with that of surface soils, where precipitation had no effect on SOC changes during woody encroachment. This inconsistency indicates that expanded data collection with a focus on SOC controls across depths is needed in such systems. Because this type of land use change has occurred on millions of hectares in the United States over the last $150 \mathrm{yr}$ (Van Auken, 2000), the effects on SOC stocks may be quite large, and data collections that close this knowledge gap will be important for accurate SOC accounting at the national scale.
Table 6. Table showing soil carbon changes during afforestation of former agricultural lands. +

\begin{tabular}{lcc}
\multicolumn{1}{c}{ Time interval } & Mean change & $\mathbf{9 5} \%$ confidence interval \\
\hline & $y r$ & \\
$<5$ & -1.2 & $(-5.4,3.2)$ \\
$5-15$ & -0.1 & $(-3.9,3.7)$ \\
$15-25$ & 1.4 & $(-2.0,4.7)$ \\
$25-35$ & 3.0 & $(-0.4,6.5)$ \\
$35-45$ & 4.5 & $(0.6,8.6)$ \\
$45-55$ & 6.1 & $(1.1,10.8)$ \\
$55-65$ & 7.7 & $(1.7,14.1)$ \\
$65-75$ & 9.3 & $(1.9,16.5)$ \\
$75-85$ & 11.0 & $(1.7,20.1)$ \\
$85-95$ & 12.6 & $(2.2,23.1)$ \\
$95-105$ & 14.4 & $(2.6,26.2)$ \\
$105-115$ & 16.1 & $(2.9,30.9)$ \\
$115-125$ & 17.8 & $(3.2,34.5)$ \\
\hline
\end{tabular}

† Mean changes (relative to nonafforested baseline) and confidence intervals are presented for the midpoint of each time interval.

Temporal patterns of SOC increase indicate the potential for significant $\mathrm{C}$ sequestration over decadal timescales on former industrial or agricultural lands, but large uncertainties within the time categories we adopted for this meta-analysis belie major underlying sources of variation. On agricultural lands, the effect size within each time category is much smaller than the $95 \%$ confidence interval ( $1 / 2$ to $1 / 5$ the magnitude), indicating that the average rate of accumulation across studies is small relative to the variation among the studies. Conversely, industrial lands show fast rates of SOC increase and have effect sizes similar in magnitude to the variation across studies. The net effect of this difference between land use types is that while both do show quantitative increases in SOC over time, afforestation causes significant SOC increases much sooner on industrial than agricultural lands (15-25 vs. 35-45 yr). However, even for the large distribution of agricultural response ratios, our meta-analysis could not identify predictive factors that drive variation in SOC change over time, indicating that site-specific data collection is more effective than literature synthesis for accurate SOC accounting of agricultural afforestations. In light of this result, it is important to consider the distribution of stand ages among agricultural afforestations and how this distribution affects the overall results of the metaanalysis described in the section Meta-analysis: Overall Results. Specifically, because $>35 \mathrm{yr}$ are required for significant, detectable increases in SOC during agricultural afforestation, but a large share of the response ratios tested in the meta-analysis had not yet reached this threshold, the effect of afforestation on SOC in agricultural soils was significant as a temporal trend rather than a categorical effect.

We used a new approach to quantify the depth distribution of SOC changes during afforestation: meta-analysis of ${ }^{13} \mathrm{C}$ mixing model data. This combination of research approaches produced results largely confirmatory of other methods. For instance, quantitative and qualitative literature reviews of basic SOC stock data have showed that superficial layers of the soil profile respond to land use changes more rapidly and to a greater degree than deeper soils (Guo and Gifford, 2002; Jandl et al., 2007). Our findings based on meta- 
analysis of isotope data thus add to prior work in affirming the widely held methodological assumption that management effects on SOC are most detectable near the top of the soil profile. At the same time, the distribution of $R_{\mathrm{SOC} 3}$ values assembled here indicates that SOC stocks in deep soils are not static—significant isotopic shifts regularly occur well below depths typically sampled by designs that emphasize change detection through shallow sampling. Although not explicitly tested in this analysis, C storage in organic horizons may be expected to be the most responsive of any portion of the soil profile, as afforestation will often lead to the development of litter, woody debris, and other surface organic matter pools that did not exist before the establishment of forest vegetation. In that regard, results of the $\mathrm{SOC}_{3}$ meta-analysis component of this work (as well as the other components) would likely show an even greater potential for increased SOC sequestration (in relative terms) than the mineral soils assessed here. Setting aside sampling considerations, the $R_{\mathrm{SOC} 3}$ values we tested in this meta-analysis were nearly all positive and most were rather large. Because $\mathrm{pSOC}_{3}$ is the net balance of two opposing gross fluxes (new forest detritus inputs and "native" $\mathrm{SOC}_{4}$ losses), $R_{\mathrm{SOC} 3}$ indicates the relative change in this net balance with afforestation-and the two gross fluxes that drive the net change in $\mathrm{pSOC}_{3}$ can simultaneously affect the absolute size of the total SOC pool. For example, $\mathrm{pSOC}_{3}$ could increase rapidly because of large new inputs and equally large losses of existing stocks, and these balanced fluxes would result in no net change in total SOC. Alternately, $\mathrm{pSOC}_{3}$ could be very small and positive as new SOC is added to the soil, but a large background of native SOC remains stable, resulting in a small net accumulation of SOC. Ultimately, the $\mathrm{pSOC}_{3}$ response ratios are a metric of how pervasive and rapid the SOC changes are in the studied soils.

If comprehensive SOC pool size data had been published for more of the ${ }^{13} \mathrm{C}$ depth profiles we synthesized in this analysis, it would have been possible to calculate gross input and output fluxes for the $\mathrm{SOC}_{3}$ and $\mathrm{SOC}_{4}$ pools and assess the SOC budgets of these soils. However, even without such an assessment, synthesis of ${ }^{13} \mathrm{C}$ depth profiles furthers our broader understanding of management and $\mathrm{C}$ dynamics in soils by indicating a surface soil zone where $\mathrm{C}$ cycling processes are consistently most affected by afforestation. This affirms the potential of afforesting soils to play a significant role in $\mathrm{C}$ sequestration, especially if the type, production rate, and stabilization mechanisms acting on $\mathrm{C}$ inputs to highly responsive surface soil can be simultaneously managed—and findings from both primary studies and quantitative reviews inform how these factors could be manipulated to promote SOC accumulation during afforestation. For example, research consistently indicates that coniferous trees decrease SOC in mineral soils during afforestation while broad-leaved hardwoods have neutral or positive effects (Guo and Gifford, 2002; Laganiere et al., 2010), perhaps through relationships between vegetation composition and structure and the amount, chemical and physical properties, and location of detritus inputs to soil (Lorenz and Lal, 2005; Sarkhot et al., 2008;

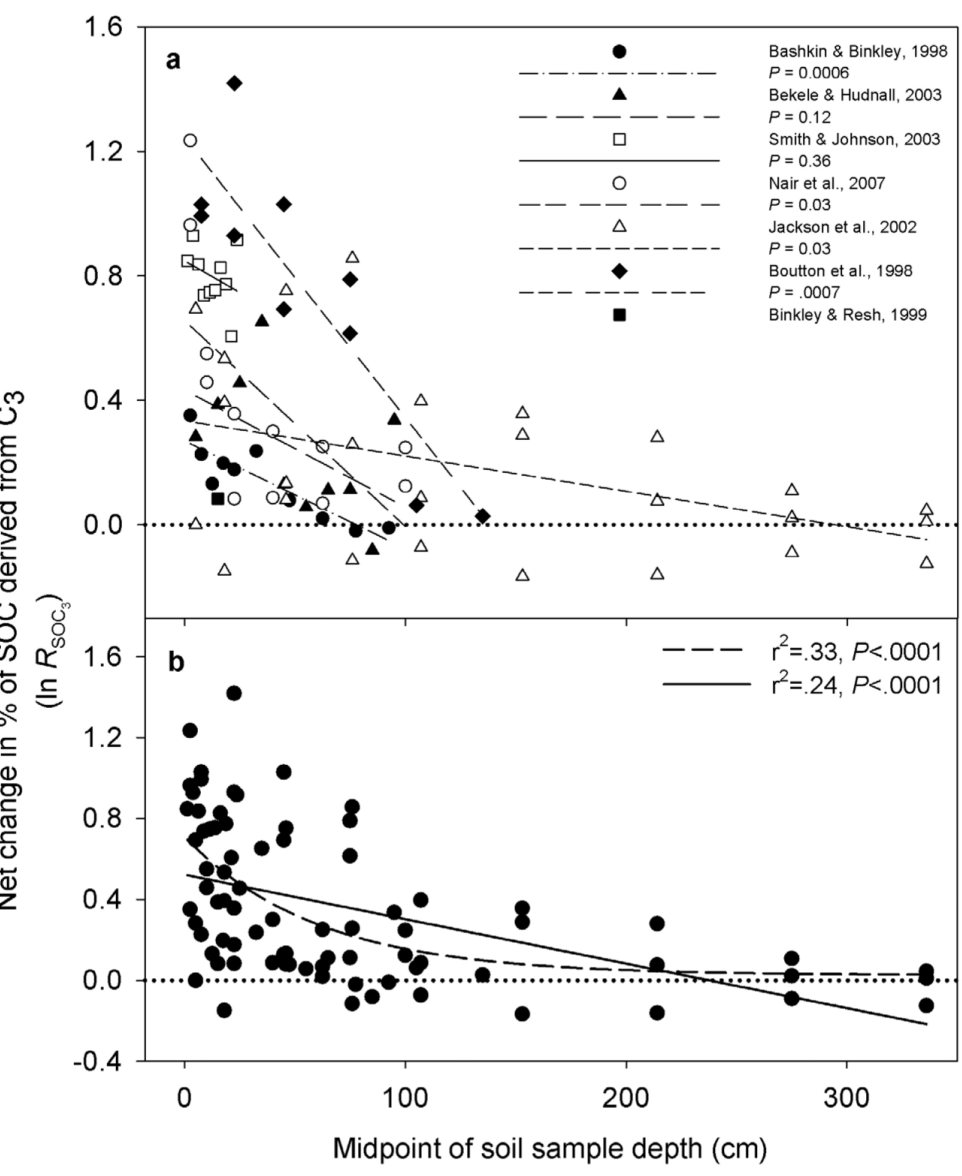

Fig. 5. Change in the fraction of SOC derived from forest (C3) inputs as a function of soil depth during afforestation of lands formerly under $\mathrm{C} 4$ vegetation. Points plotted are individual, In-transformed response ratios. (a) Response ratios and best-fit statistics for the individual papers included in this part of the analysis (see Appendix B). (b) Distribution of response ratios across all papers, with best-fit statistics for continuous meta-analytic and nonlinear regression models.

Shan et al., 2001). However, even if coniferous trees release native SOC from deeper portions of the profile, these species tend to drive surface organic layer accumulation, a process which can dramatically affect the $\mathrm{C}$ balance of an afforestating ecosystem (Laganiere et al., 2010). In the context of the responsive surface soil zone identified by our meta-analysis of $\mathrm{SOC}_{3}$ data, the generalized difference between coniferous and broadleaved trees could be used to target SOC accumulation in particular portions of the soil profile, depending on the goals of the afforestation project. Laganiere et al. (2010) also found in their global meta-analysis that soils with higher clay content had higher capacity for SOC increase, congruent with the important role of organo-mineral interactions in forming stabilized SOC from plant- and microbe-derived C inputs (Kleber et al., 2010; Schmidt et al., 2011). Because interactions with microbial biomass can also promote the growth of stabilized SOC pools through aggregation and physical protection mechanisms (Godbold et al., 2006; Langley and Hungate, 2003; Rillig, 2004; Rillig et al., 2001), forest establishment on finetextured soils or the use of mycorrhizal inoculation could be used to accelerate SOC accumulation during afforestation.

One of the principal justifications for the meta-analysis portion of this synthesis paper is that the global scope of existing affor- 


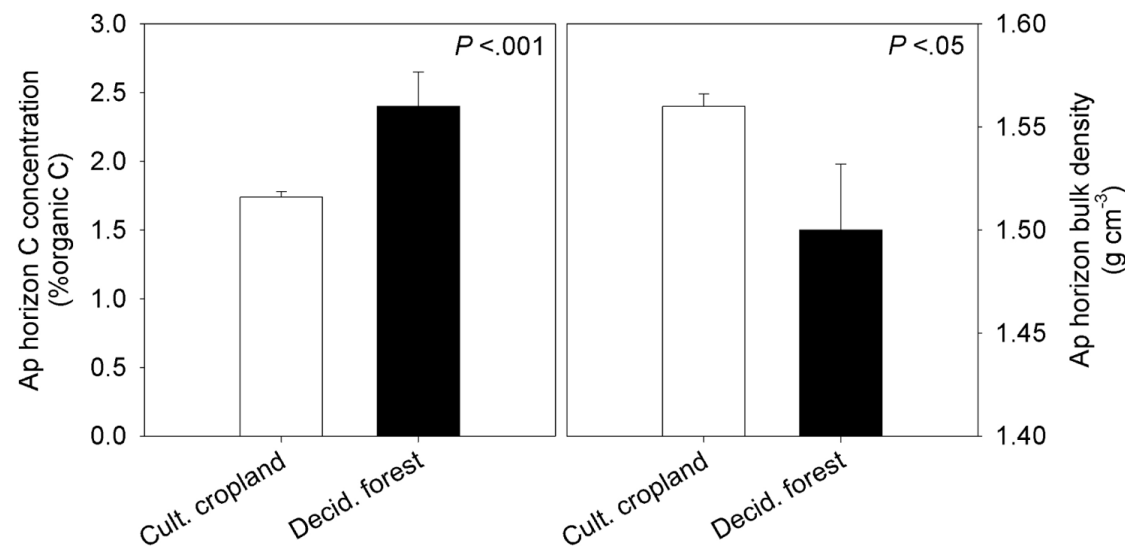

Fig. 6. Carbon concentrations (left panel) and bulk densities (right panel) of Ap horizons from cultivated vs. forested land cover types. Bars are means with errors expressed as SE. detritus inputs have augmented SOC stocks depleted during cultivation. Widespread conversion of agricultural land to forests is currently unlikely, but there is potential to introduce limited afforestation into active agricultural lands. Importantly, afforestation need not occur at the expense of crop production, because approaches like alley cropping, shelterbelt planting, and afforestation of buffer strips can incorporate trees into agricultural landscapes with no loss, or even gains in crop or livestock production (Bird, 1998; Garrett et al., 2004; Jose et al., 2000; Miller and Pallardy, 2001; Mize et al., 2005). At the same time, however, such limited-scale afforestation approaches are
estation-SOC meta-analyses makes their direct application to the United States uncertain. Qualitatively, our meta-analysis reaffirmed the findings of global reviews in that (i) previous land use was the major driver of SOC change and (ii) changes in SOC are greatest near the top of the soil profile. However, our meta-analysis did not confirm other important findings of global reviews, such as a difference between coniferous and broadleaved tree species or any covariance between SOC change and soil texture during afforestation. This could indicate that, within the geographic scope of the United States, such factors do not vary sufficiently to drive significant variation in SOC change but is more likely due to a limited availability of data from widely distributed sites. With 282 response ratios from 39 papers, the database we tested in the present meta-analysis was not insubstantial and indeed was still sufficient to constrain significant temporal trajectories of $\mathrm{SOC}$ change for several previous land uses. Nonetheless, it is clear from the abundant unexplained variability and site specificity in this analysis that more data are needed for tightly constrained estimates of SOC change during afforestation or balanced comparisons with other reviews.

Our geospatial analysis of $\mathrm{SOC}$ contents from forested vs. cultivated Ap horizons indicates that afforestation has increased SOC sequestration at locations throughout the Northern Prairie region of the United States. In once-plowed A horizons now under forest cover, higher \%C and SOC likely indicate locations where new

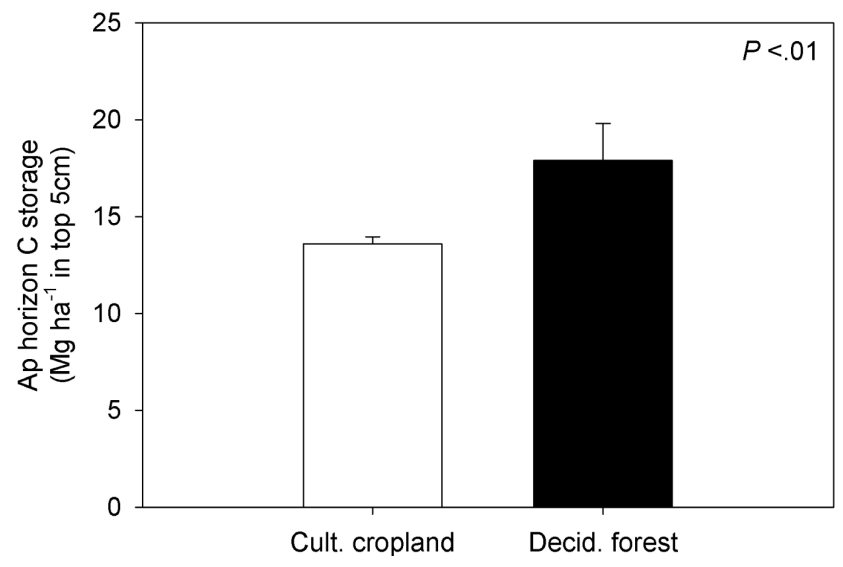

Fig. 7. Soil C stocks in the upper $5 \mathrm{~cm}$ of Ap horizons from cultivated vs. forested soils. Means and SEs plotted. not likely to produce the same degree of ecosystem C sequestration as larger-scale projects, such as the wholesale establishment of plantations on large areas of degraded lands. Afforestation of depleted croplands for soil quality remediation requires a longerterm concept of crop rotation but could also be used to increase SOC in locations that have suffered extreme losses of soil productivity (Wilde, 1964; Richter et al., 1999). Regardless of how afforestation is incorporated into agricultural settings, our geospatial and meta-analysis results indicate that this management decision will typically increase SOC. These results are contextualized by the geographically broader meta-analysis of Guo and Gifford (2002), which revealed that the net SOC increase due to afforesting agricultural land approximates the net SOC loss observed when forests are converted to agriculture. In this sense, the benefit of afforestation on former U.S. agricultural lands from a soil $\mathrm{C}$ perspective appears to be the recovery of soil C stocks that have been lost since forest clearing began 1 to 2 centuries ago across much of the country (Birdsey et al., 2006).

\section{CONCLUSION}

The results of our synthesis indicate that, in general, soils undergoing afforestation in the United States are increasing their SOC stocks, especially in surficial layers. However, this result must be considered in the context of several findings of our meta-analysis. First, categorically significant SOC increases were associated with afforestation on reclaimed industrial lands or unmanaged wildlands invaded by woody vegetation but not on former agricultural lands. Temporal patterns of SOC change during afforestation indicate that agricultural lands do increase SOC storage, but that several decades are typically required to reach significant, detectable levels (as is also the case with reclaimed industrial lands). Lastly, significant, unexplained variability in soil C responses to afforestation (especially on agricultural or unmanaged lands) indicates substantial site-specificity in the effects of afforestation on soil C storage. This argues strongly for project-specific SOC measurements whenever possible, both for $\mathrm{C}$ accounting of land use changes and for the sake of increasing data availability for future modeling and meta-analysis. 


\section{APPENDIX A.}

Data sources used in the overall meta-analysis of afforestation impacts on SOC.

\section{Reference}

Akala and Lal, 2000

Arevalo et al., 2009

Bambrick et al., 2010

Bashkin and Binkley, 1998

Binkley and Resh, 1999

Christenson and MacAller, 1985

Coleman et al., 2004

De Gryze et al., 2004

Dowell et al., 2009

Grigal and Berguson, 1998

Hamburg, 1984

Hansen, 1993

Hooker and Compton, 2003

Hosner and Graney, 1970

Jackson et al., 2002

Leisman, 1957

Liao et al., 2006

Markewitz et al., 2002

Martens et al., 2003

McKinley and Blair, 2008

Montes and Christenson, 1979

Morris et al., 2007

Nair et al., 2007

Neff et al., 2009

Paul et al., 2003

Peichl and Arain, 2006

Pregitzer and Palik, 1997

Richter et al., 1999

Rolfe and Boggess, 1973

Sartori et al., 2007

Sauer et al., 2007

Scharenbroch et al., 2010

Schiffman and Johnson, 1989

Sharrow and Ismail, 2004

Sherman and Beckett

Smith et al., 1997

Springsteen et al., 2010

Zou and Bashkin, 1998

\begin{tabular}{|c|c|}
\hline Dominant canopy genera & Locations \\
\hline Pinus, Acer & $\mathrm{OH}$ (USA) \\
\hline Populus & $\mathrm{AB}(\mathrm{CA})$ \\
\hline Picea, Populus & ON, QC (CA) \\
\hline Eucalyptus & HI (USA) \\
\hline Eucalyptus & HI (USA) \\
\hline Pinus & $\mathrm{NC}($ USA) \\
\hline Populus & $M N, W I, I A, N D(U S A)$ \\
\hline Populus, Pinus & MI (USA) \\
\hline Populus & $\mathrm{MO}(\mathrm{USA})$ \\
\hline Populus & MN (USA) \\
\hline Acer, Picea & $\mathrm{NH}(\mathrm{USA})$ \\
\hline Populus & $M N, W I, I A, N D(U S A)$ \\
\hline Pinus & RI (USA) \\
\hline Pinus & VA (USA) \\
\hline Prosopis, Larrea & TX, NM, CO (USA) \\
\hline Populus, Prunus & MN (USA) \\
\hline Prosopis & TX (USA) \\
\hline Pinus & GA (USA) \\
\hline Prunus, Robinia & NE (USA) \\
\hline Juniperus & KS (USA) \\
\hline Pinus, Liquidambar & NC (USA) \\
\hline Acer, Quercus & MI (USA) \\
\hline Pinus & FL (USA) \\
\hline Pinus, Juniperus & UT (USA) \\
\hline Acer, Pinus & $\mathrm{OH}(\mathrm{USA}), \mathrm{ON}(\mathrm{CA})$ \\
\hline Pinus & $\mathrm{ON}(\mathrm{CA})$ \\
\hline Pinus & WI (USA) \\
\hline Pinus & SC (USA) \\
\hline Pinus & IL (USA) \\
\hline Populus & OR (USA) \\
\hline Juniperus, Pinus & NE (USA) \\
\hline Quercus, Pinus & WI (USA) \\
\hline Pinus & VA (USA) \\
\hline Pseudotsuga & OR (USA) \\
\hline Pinus & ON (CA) \\
\hline Pinus, Betula & CT (USA) \\
\hline Amelanchier, Sheperdia & ND (USA) \\
\hline Eucalyptus & HI (USA) \\
\hline
\end{tabular}

\section{APPENDIX B.}

Data sources used in the meta-analysis of soil ${ }^{13} \mathrm{C}$ data.

\begin{tabular}{lll}
\multicolumn{1}{c}{ Reference } & \multicolumn{1}{c}{ Previous land use } & \multicolumn{1}{c}{ Locations } \\
Bashkin and Binkley, 1998 & Cultivated & HI (USA) \\
Bekele and Hudnall, 2003 & Unmanaged & LA (USA) \\
Binkley and Resh, 1999 & Cultivated & HI (USA) \\
Boutton et al., 1998 & Unmanaged & TX (USA) \\
Jackson et al., 2002 & Unmanaged & CO, NM, TX (USA) \\
Nair et al., 2007 & Forage & FL (USA) \\
Smith and Johnson, 2003 & Unmanaged & KS (USA) \\
\hline
\end{tabular}

\section{ACKNOWLEDGMENTS}

This work was supported by agreements no. 10-CR-11242306-113 and 06-JV-11242300 from the USDA-Forest Service, Northern Research Station, and award no. 2009-02612 from the USDA-National Institute of Food and Agriculture. The project was facilitated by the National Soil Carbon Network, and benefited from extensive data contributions to the NSCN from the USDA-Natural Resources Conservation Service, and National Cooperative Soil Survey (Soil Survey Staff, 2011). The authors thank Rich Birdsey, Peter Curtis, Alex Friend, Kyle Kwaiser, and Eric Vance for helping to define the scope, criteria, and methods for this synthesis project; Dan Richter and Megan Mobley for sharing unpublished data from the Calhoun Experimental Forest; and two anonymous reviewers for helpful comments that improved the manuscript from its draft version.

\section{REFERENCES}

Adams, D.C., J. Gurevitch, and M.S. Rosenberg. 1997. Resampling tests for metaanalysis of ecological data. Ecology 78:1277-1283. doi:10.1890/00129658(1997)078[1277:RTFMAO]2.0.CO;2

Akala, V.A., and R. Lal. 2000. Potential of mine land reclamation for soil organic carbon sequestration in Ohio. Land Degrad. Dev. 11:289-297. doi:10.1002/1099-145X(200005/06)11:3<289::AIDLDR385>3.0.CO;2-Y

Alvarez, R. 2005. A review of nitrogen fertilizer and conservation tillage effects on soil organic carbon storage. Soil Use Manage. 21:38-52. doi:10.1079/ SUM2005291

Amichev, B.Y., J.A. Burger, and J.A. Rodrigue. 2008. Carbon sequestration by forests and soils on mined land in the Midwestern and Appalachian coalfields of the US. For. Ecol. Manage. 256: 1949-1959.

Arevalo, C.B.M., J.S. Bhatti, S.X. Chang, and D. Sidders. 2009. Ecosystem carbon stocks and distribution under different land-uses in north central Alberta, Canada. For. Ecol. Manage. 257:1776-1785. doi:10.1016/j. foreco.2009.01.034

Balesdent, J., G.H. Wagner, and A. Mariotti. 1988. Soil organic-matter turnover in long-term field experiments as revealed by Carbon-13 natural abundance. Soil Sci. Soc. Am. J. 52:118-124. doi:10.2136/ sssaj1988.03615995005200010021x

Bambrick, A.D., J.K. Whalen, R.L. Bradley, A. Cogliastro, A.M. Gordon, A. Olivier, and N.V. Thevathasan. 2010. Spatial heterogeneity of soil organic carbon in tree-based intercropping systems in Quebec and Ontario, Canada. Agrofor. Syst. 79:343-353. doi:10.1007/s10457-010-9305-z

Bashkin, M.A., and D. Binkley. 1998. Changes in soil carbon following afforestation in Hawaii. Ecology 79:828-833. doi:10.1890/00129658(1998)079[0828:CISCFA]2.0.CO;2

Berthrong, S.T., E.G. Jobbagy, and R.B. Jackson. 2009. A global meta-analysis of soil exchangeable cations, $\mathrm{pH}$, carbon, and nitrogen with afforestation. Ecol. Appl. 19:2228-2241. doi:10.1890/08-1730.1

Binkley, D., and S.C. Resh. 1999. Rapid changes in soils following Eucalyptus afforestation in Hawaii. Soil Sci. Soc. Am. J. 63:222-225. doi:10.2136/ sssaj1999.03615995006300010032x

Bird, P.R. 1998. Tree windbreaks and shelter benefits to pasture in temperate grazing systems. Agrofor. Syst. 41:35-54. doi:10.1023/A:1006092104201

Birdsey, R., K. Pregitzer, and A. Lucier. 2006. Forest carbon management in the United States. J. Environ. Qual. 35:1461-1469. doi:10.2134/jeq2005.0162

Boutton, T.W., S.R. Archer, A.J. Midwood, S.F. Zitzer, and R. Bol. 1998. $8^{13} \mathrm{C}$ values of soil organic carbon and their use in documenting vegetation change in a subtropical savanna ecosystem. Geoderma 82:5-41. doi:10.1016/S0016-7061(97)00095-5

Christensen, N.L., and T. MacAller. 1985. Soil mineral nitrogen transformations during succession in the Piedmont of North Carolina. Soil Biol. Biochem. 17:675-681. doi:10.1016/0038-0717(85)90045-8

Coleman, M., J. Isebrands, D. Tolsted, and V. Tolbert. 2004. Comparing soil carbon of short rotation poplar plantations with agricultural crops and woodlots in North Central United States. Environ. Manage. 33:S299S308. doi:10.1007/s00267-003-9139-9

Compton, J.E., and R.D. Boone. 2000. Long-term impacts of agriculture on soil carbon and nitrogen in New England forests. Ecology 81: 2314-2330.

DeGryze, S., J. Six, K. Paustian, S.J. Morris, E.A. Paul, and R. Merck. 2004. 
Soil organic carbon pool changes following land-use conversions. Glob. Change Biol. 10:1120-1132. doi:10.1111/j.1529-8817.2003.00786.x

Dowell, R.C., D. Gibbins, J.L. Rhoads, and S.G. Pallardy. 2009. Biomass production physiology and soil carbon dynamics in short-rotation-grown Populus deltoides and $P$. deltoides ' $P$. nigra hybrids. For. Ecol. Manage. 257:134-142. doi:10.1016/j.foreco.2008.08.023

Fox, T.R. 2000. Sustained productivity in intensively managed forest plantations. For. Ecol. Manage. 138:187-202. doi:10.1016/S0378-1127(00)00396-0

Garrett, H.E., M.S. Kerley, K.P. Ladyman, W.D. Walter, L.D. Godsey, J.W. Van Sambeek, and D.K. Brauer. 2004. Hardwood silvopasture management in North America. Agrofor. Syst. 61-62:21-33. doi:10.1023/ B:AGFO.0000028987.09206.6b

Godbold, D.L., et al. 2006. Mycorrhizal hyphal turnover as a dominant process for carbon input into soil organic matter. Plant Soil 281:15-24. doi:10.1007/s11104-005-3701-6

Grigal, D.F., and W.E. Berguson. 1998. Soil carbon changes associated with short-rotation systems. Biomass Bioenergy 14:371-377. doi:10.1016/ S0961-9534(97)10073-3

Guo, L.B., and R.M. Gifford. 2002. Soil carbon stocks and land use change: A meta analysis. Glob. Change Biol. 8:345-360. doi:10.1046/j.13541013.2002.00486.x

Hamburg, S.P. 1984. Effects of forest growth on soil nitrogen and organic matter pools following release from subsistence agriculture. In: E.L. Stone, editor, Proceedings of the 6th North American Forest Soils Conference, Knoxville, TN. June 1983. Univ. of Tennessee, Knoxville. p. 145-148.

Hansen, E.A. 1993. Soil carbon sequestration beneath hybrid poplar plantations in the North Central United States. Biomass Bioenergy 5:431-436. doi:10.1016/0961-9534(93)90038-6

Hedges, L.V., and I. Olkin. 1985. Statistical methods for meta-analysis. Academic Press, New York.

Hedges, L.V., J. Gurevitch, and P.S. Curtis. 1999. The meta-analysis of response ratios in experimental ecology. Ecology 80:1150-1156. doi:10.1890/00129658(1999)080[1150:TMAORR]2.0.CO;2

Hooker, T.D., and J.E. Compton. 2003. Forest ecosystem carbon and nitrogen accumulation during the first century after agricultural abandonment. Ecol. Appl. 13:299-313. doi:10.1890/1051-0761(2003)013[0299:FEC ANA]2.0.CO;2

Hosner, J.F., and D.L. Graney. 1970. The relative growth of three forest tree species on soils associated with different successional stages in Virginia. Am. Midl. Nat. 84:418-427. doi:10.2307/2423857

Jackson, R.B., J.L. Banner, E.G. Jobbagy, W.T. Pockman, and D.H. Wall. 2002. Ecosystem carbon loss with woody plant invasion of grasslands. Nature 418:623-626. doi:10.1038/nature00910

Jandl, R., M. Lindner, L. Vesterdal, B. Bauwens, R. Baritz, F. Hagedorn, D.W. Johnson, K. Minkkinen, and K.A. Byrne. 2007. How strongly can forest management influence soil carbon sequestration? Geoderma 137:253268. doi:10.1016/j.geoderma.2006.09.003

Jobbágy, E.G., and R.B. Jackson. 2000. The vertical distribution of soil organic carbon and its relation to climate and vegetation. Ecol. Appl. 10:423-436. doi:10.1890/1051-0761(2000)010[0423:TVDOSO]2.0.CO;2

Jose, S., A.R. Gillespie, J.R. Seifert, and D.J. Biehle. 2000. Defining competition vectors in a temperate alley cropping system in the midwestern USA: 2. Competition for water. Agrofor. Syst. 48:41-59. doi:10.1023/A:1006289322392

Kleber, M., P.S. Nico, A. Plante, T. Filley, M. Kramer, C. Swanston, and P. Sollins. 2010. Old and stable soil organic matter is not necessarily chemically recalcitrant: Implications for modeling concepts and temperature sensitivity. Glob. Change Biol. 17:1097-1107.doi:10.1111/j.1365-2486.2010.02278.x

Ladha, J.K., C.K. Reddy, A.T. Padre, and C. van Kessel. 2011. Role of nitrogen fertilization in sustaining organic matter in cultivated soils. J. Environ. Qual. 40:1756-1766. doi:10.2134/jeq2011.0064

Laganiere, J., D.A. Angers, and D. Pare. 2010. Carbon accumulation in agricultural soils after afforestation: A meta-analysis. Glob. Change Biol. 16:439-453. doi:10.1111/j.1365-2486.2009.01930.x

Lal, R. 2004. Soil carbon sequestration to mitigate climate change. Geoderma 123:1-22. doi:10.1016/j.geoderma.2004.01.032

Langley, J.A., and B.A. Hungate. 2003. Mycorrhizal controls on belowground litter quality. Ecology 84:2302-2312. doi:10.1890/02-0282

Leisman, G.A. 1957. A vegetation and soil chronosequence on the Mesabi iron range spoil banks, Minnesota. Ecol. Monogr. 27:221-245. doi:10.2307/1942184

Liao, J.D., T.W. Boutton, and J.D. Jastrowe. 2006. Storage and dynamics of carbon and nitrogen in soil physical fractions following woody plant invasion of grassland. Soil Biol. Biochem. 38:3184-3196. doi:10.1016/j. soilbio.2006.04.003

Lorenz, K., and R. Lal. 2005. The depth distribution of soil organic carbon in relation to land use and management and the potential of carbon sequestration in subsoil horizons. In: D. Sparks, editor, Advances in agronomy. Vol. 88. London, Academic Press. p. 35-66.

Ludwig, B., et al. 2011. Effects of fertilization and soil management on crop yields and carbon stabilization in soils. A review. Agron. Sustain. Dev. 31:361-372.

Markewitz, D., F. Sartori, and C. Craft. 2002. Soil change and carbon storage in longleaf pine stands planted on marginal agricultural lands. Ecol. Appl. 12:1276-1285. doi:10.1890/1051-0761(2002)012[1276:SCACSI]2.0.CO;2

Martens, D.A., T.E. Reedy, and D.T. Lewis. 2004. Soil organic carbon content and composition of 130-year crop, pasture and forest land-use managements. Glob. Change Biol. 10:65-78. doi:10.1046/j.1529-8817.2003.00722.x

McKinley, D.C., and J.M. Blair. 2008. Woody plant encroachment by Juniperus virginiana in a mesic native grassland promotes rapid carbon and nitrogen accrual. Ecosystems 11:454-468. doi:10.1007/s10021-008-9133-4

Miller, A.W., and S.G. Pallardy. 2001. Resource competition across the croptree interface in a maize-silver maple temperate alley cropping stand in Missouri. Agrofor. Syst. 53:247-259. doi:10.1023/A:1013327510748

Mize, C.W., M.H.Egeh, and W.D. Batchelor. 2005. Predicting maize and soybean production in a sheltered field in the Cornbelt region of North Central USA. Agrofor. Syst. 64:107-116. doi:10.1007/s10457-004-0534-x

Montes, R.A., and N.L. Christenson. 1979. Nitrification and succession in the Piedmont of North Carolina. For. Sci. 25:287-297.

Morris, S.J., S. Bohm, S. Haile-Mariam, and E.A. Paul. 2007. Evaluation of carbon accrual in afforested agricultural soils. Glob. Change Biol. 13:1145-1156. doi:10.1111/j.1365-2486.2007.01359.x

Multi-Resolution Land Characteristics Consortium. 2011. 2001 National land cover data (NLCD 2001). USEPA. www.epa.gov/mrlc/nlcd-2001.html (accessed 20 Feb. 2011).

Nair, V.D., S.G. Haile, G.A. Michel, and P.K.R. Nair. 2007. Environmental quality improvement of agricultural lands through silvopasture in southeastern United States. Sci. Agric. 64:513-519. doi:10.1590/S010390162007000500009

Nave, L.E., E.D. Vance, C.W. Swanston, and P.S. Curtis. 2009. Impacts of elevated N inputs on north temperate forest soil C storage, $\mathrm{C} / \mathrm{N}$, and net $\mathrm{N}$-mineralization. Geoderma 153:231-240. doi:10.1016/j.geoderma.2009.08.012

Nave, L.E., E.D. Vance, C.W. Swanston, and P.S. Curtis. 2010. Harvest impacts on soil carbon storage in temperate forests. For. Ecol. Manage. 259:857866. doi:10.1016/j.foreco.2009.12.009

Neff, J.C., N.N. Barger, W.T. Baisden, D.P. Fernandez, and G.P. Asner. 2009. Soil carbon storage responses to expanding pinyon-juniper populations in southern Utah. Ecol. Appl. 19:1405-1416. doi:10.1890/08-0784.1

Paul, K.I., P.J. Polglase, J.G. Nyakuengama, and P.K. Khanna. 2002. Change in soil carbon following afforestation. For. Ecol. Manage. 168:241-257. doi:10.1016/S0378-1127(01)00740-X

Paul, E.A., S.J. Morris, J. Six, K. Paustian, and E.G. Gregorich. 2003. Interpretation of soil carbon and nitrogen dynamics in agricultural and afforested soils. Soil Sci. Soc. Am. J. 67:1620-1628. doi:10.2136/sssaj2003.1620

Peichl, M., and A.A. Arain. 2006. Above- and belowground ecosystem biomass and carbon pools in an age-sequence of temperate pine plantation forests. Agric. For. Meteorol. 140:51-63. doi:10.1016/j.agrformet.2006.08.004

Post, W.M., R.C. Izaurralde, J.D. Jastrow, B.A. McCarl, J.E. Amonette, V.L. Bailey, P.M. Jardine, T.O. West, and J. Zhou. 2004. Enhancement of carbon sequestration in US soils. Bioscience 54:895-908. doi:10.1641/00063568(2004)054[0895:EOCSIU]2.0.CO;2

Post, W.M., and K.C. Kwon. 2000. Soil carbon sequestration and landuse change: Processes and potential. Glob. Change Biol. 6:317-327. doi:10.1046/j.1365-2486.2000.00308.x

Pregitzer, K., and B. Palik. 1997. Changes in ecosystem carbon 46 years after establishing red pine (Pinus resinosa Ait.) on abandoned agricultural land in the Great Lakes region. In: E.A. Paul et al., editors, Soil organic matter in temperate agroecosystems: Long-term experiments in North America, CRC Press, Boca Raton, FL. p. 263-270.

Richter, D.D., D. Markewitz, S.E. Trumbore, and C.G. Wells. 1999. Rapid accumulation and turnover of soil carbon in a re-establishing forest. Nature 
400:56-58. doi: $10.1038 / 21867$

Rillig, M.C. 2004. Arbuscular mycorrhizae, glomalin, and soil aggregation. Can. J. Soil Sci. 84:355-363. doi:10.4141/S04-003

Rillig, M.C., S.F. Wright, K.A. Nichols, W.F. Schmidt, and M.S. Torn. 2001. Large contribution of arbuscular mycorrhizal fungi to soil carbon pools in tropical forest soils. Plant Soil 233:167-177. doi:10.1023/A:1010364221169

Rolfe, G.L., and W.R. Boggess. 1973. Soil conditions under old field and forest cover in southern Illinois. Soil Sci. Soc. Am. J. 37:314-318. doi:10.2136/ sssaj1973.03615995003700020040x

Rosenberg, M.S., D.C. Adams, and J. Gurevitch. 2000. MetaWin: Statistical software for meta-analysis. Sinauer Assoc., Sunderland, MA.

Sarkhot, D.V., E.J. Jokela, and N.B. Comerford. 2008. Surface soil carbon sizedensity fractions altered by loblolly pine families and forest management intensity for a Spodosol in the southeastern US. Plant Soil 307:99-111. doi:10.1007/s11104-008-9587-3

Sartori, F., R. Lal, M.H. Ebinger, and J.A. Eaton. 2007. Changes in soil carbon and nutrient pools along a chronosequence of poplar plantations in the Columbia Plateau, Oregon, USA. Agric. Ecosyst. Environ. 122:325-339. doi:10.1016/j.agee.2007.01.026

Sauer, T.J., C.A. Cambardella, and J.R. Brandle. 2007. Soil carbon and tree litter dynamics in a red cedar-scotch pine shelterbelt. Agrofor. Syst. 71:163-174. doi:10.1007/s10457-007-9072-7

Scharenbroch, B.C., M.L. Flores-Mangual, B. Lepore, J.G. Bockheim, and B. Lowery. 2010. Tree encroachment impacts carbon dynamics in a sand prairie in Wisconsin. Soil Sci. Soc. Am. J. 74:956-968. doi:10.2136/sssaj2009.0223

Schiffman, P.M., and W.C. Johnson. 1989. Phytomass and detrital carbon storage during forest regrowth in the southeastern U.S. piedmont. Can. J. For. Res. 19:69-78. doi:10.1139/x89-010

Schmidt, M.W., et al.. 2011. Persistence of soil organic matter as an ecosystem property. Nature 478:49-56. doi:10.1038/nature 10386

Shan, J.P., L.A. Morris, and R.L. Hendrick. 2001. The effects of management on soil and plant carbon sequestration in slash pine plantations. J. Appl. Ecol. 38:932-941. doi:10.1046/j.1365-2664.2001.00648.x

Sharrow, S.H., and S. Ismail. 2004. Carbon and nitrogen storage in agroforests, tree plantations, and pastures in western Oregon, USA. Agrofor. Syst. 60:123-130. doi:10.1023/B:AGFO.0000013267.87896.41

Sherman, G.G., and P.J. Beckett. 2003. Carbon sequestration patterns in the replanted areas of the Sudbury barrens. Forest Research Information Paper. Ontario For. Res. Inst., Ontario, Canada.

Smith, F.C., A.H. Johnson, M. Dranoff, and A. Wibiralske. 1997. Biomass and nutrient accumulation during natural afforestation of iron-smelting slag. Restor. Ecol. 5:56-65. doi:10.1046/j.1526-100X.1997.09706.x

Smith, J.E., L.S. Heath, K.E. Skog, and R.A. Birdsey. 2006. Methods for calculating forest ecosystem and harvested carbon with standard estimates for forest types of the U.S. GTR NE-343. U.S. Dep. of Agric., For. Serv., Northeastern Res. Stn., Newtown Square, PA.

Soil Survey Staff. 2011. National Cooperative Soil Characterization Data. Soil Survey Laboratory, National Soil Survey Center, USDA-Natural Resources Conservation Service, Lincoln, NE. http://ssldata.nrcs.usda. gov (accessed 11 Jan. 2011).

Springsteen, A., W. Loya, M. Liebig, and J. Hendrickson. 2010. Soil carbon and nitrogen across a chronosequence of woody plant expansion in North Dakota. Plant Soil 328:369-379. doi:10.1007/s11104-009-0117-8

Thiffault, E., K.D. Hannam, D. Pare, B.D. Titus, P.W. Hazlett, D.G. Maynard, and S. Brais. 2011. Effects of forest biomass harvesting on soil productivity in boreal and temperate forests-A review. Environ. Rev. 19:278-309. doi:10.1139/a11-009

Van Auken, O.W. 2000. Shrub invasions of North American semiarid grasslands. Annu. Rev. Ecol. Syst. 31:197-215. doi:10.1146/annurev.ecolsys.31.1.197

Vance, E.D. 2000. Agricultural site productivity: Principles derived from longterm experiments and their implications for intensively managed forests. For. Ecol. Manage. 138:369-396. doi:10.1016/S0378-1127(00)00425-4

Vitorello, V.A., C.C. Cerri, F. Andreux, C. Feller, and R.L. Victoria. 1989. Organic matter and natural carbon-13 distribution in forested and cultivated oxisols. Soil Sci. Soc. Am. J. 53:773-778. doi:10.2136/ sssaj1989.03615995005300030024x

Wilde, S.A. 1964. Changes in soil productivity induced by pine plantations. Soil Sci. 97:276-278. doi:10.1097/00010694-196404000-00009

Wilhelm, W.W., J.M.F. Johnson, J.L. Hatfield, W.B. Voorhees, and D.R. Linden. 2004. Crop and soil productivity response to corn residue removal: A literature review. Agron. J. 96:1-17. doi:10.2134/agronj2004.0001

Zou, X., and M.A. Bashkin. 1998. Soil carbon accretion and earthworm recovery following revegetation in abandoned sugarcane fields. Soil Biol. Biochem. 30:825-830. doi:10.1016/S0038-0717(97)00155-7 